Sven Hauff, Daniela Rastetter ${ }^{*}$

\title{
Good Work: Eroding and New Standards in a Changing World
}

The changing context of work - for example, through globalization, intensification of competition, deregulation, growth in employment flexibility, technological changes, digitalization, or the Covid-19 pandemic - increasingly triggers debates about the quality of working life. Grote and Guest (2017), for example, recently made a "case for reinvigorating quality of working life research" and Warhurst and Knox (2020) just published a "Manifesto for a New Quality of Working Life". These debates are evoked by concerns about the well-being of employees which seems to become more and more threatened through contemporary developments in work and society. For example, while changes in technology enable employees to better access information or to work more flexible, they can also lead, for instance, to increased demands through work intensification or work-home interference, loss of control, and higher job insecurity. Another example is the Covid-19 pandemic which changed the working situation of employees around the globe leading to increases in working hours, job insecurity and large inequalities between different groups of employees (e.g. Eurofound, 2020).

Such observations sometimes elicit nostalgic memories of the apparently 'good old days' where work was characterized by full-time employment, an adequate income, a permanent contract, and social insurance. However, these 'old' standards of 'good work' did not apply to all employees and even in the 'good old days', work was often characterized by a strict hierarchy and low influence, where employees' interests were largely neglected. Here, modern forms of employment - often discussed under the heading of 'new work' - could lead to improvements by providing, for example, more autonomy, involvement, flexible working hours, flexibility in the location of work, a better worklife balance, and inclusion (Aroles et al., 2019).

The question of how to evaluate the changes in the world of work is not easy and there are manifold perspectives on how to define the standards of 'good work'. A first perspective is to identify the work and employment conditions that are beneficial (or threatening) for employee well-being. This usually leads to lists of aspects that are considered to contribute to employee well-being. For example, the International Labour Organization (ILO) provides a framework of Decent Work Indicators that includes employment opportunities, adequate earnings and productive work, decent working time, combining work, family and personal life,

* Prof. Dr. Sven Hauff, Department of Humanities and Social Sciences, Helmut Schmidt University Hamburg. E-Mail: hauff@hsu-hh.de

Prof. Dr. Daniela Rastetter, Department of Socioeconomics, University of Hamburg. E-Mail: Daniela.Rastetter@uni-hamburg.de

mrev, 32 (3) 2021, 147-151 
work that should be abolished, work stability and security, equal opportunity and treatment in employment, a safe work environment, social security, social dialogue and employers' and workers' representation (ILO, 2013). Similar, Grote and Guest (2017) consider adequate and fair compensation, safe and healthy environment, development of human capacities, growth and security, social integration, constitutionalism, consideration of the total life space, social relevance, individual proactivity, and flexible working as the key criteria of 'good work'.

The latter list represents a "renewed quality of working life framework" (Grote \& Guest, 2017, p. 149) that extends the original quality of working life criteria elaborated in the 1960s and 1970s (Walton, 1973). Thus, research does not only offer various conceptualisations but also the view on which work and employment conditions are indicative of good work is changing over time. A particular challenge here is the multidimensional nature of employee well-being, which includes aspects like physical and mental health, satisfaction, engagement or social well-being. Given this multidimensionality, work and employment conditions can have a differentiated impact on the different dimensions of employee well-being and there might even be trade-offs, i.e. that work and employment conditions can improve one dimension of employee well-being while undermining another (Guerci et al., 2019). For example, while job autonomy might lead to higher job satisfaction, it also bears the risk of increasing demands with negative effects on employees' health.

The identification and analysis of different indicators of good work can provide detailed information on work and employment conditions and how they change over time. However, looking at specific work and employment conditions does not allow an assessment of the overall quality of working life and its change. In order to address this issue, researchers have created indices to measure the quality of working life (e.g. Leschke \& Watt, 2014) or have analysed patterns at the job level (e.g. Holman, 2013). Index approaches aggregate various work and employment conditions to an overall measure in order to provide a holistic assessment of the quality of working life. The analysis of patterns at the job level refers to the idea that jobs are comprised of multiple resources and demands that together determine the quality of a job. Both approaches can be used to define standards of good work either in terms of a specific value of a job quality index or as a specific job type that adequately balances the resources and demands of a job.

The aforementioned approaches follow an objectivist understanding of job quality where the standards of good work are defined by researchers who identify the work and employment conditions that are supposed to influence the well-being of employees. This can be contrasted with a subjectivist understanding which puts more emphasis on the individual perception of work and employment conditions. Research has often shown that an objectively 'bad' job (e.g. a job with low discretion, low income and low job security) can be perceived as subjectively 'good' by workers (Knox et al., 2014). Of particular importance are work values which signify 
what employees desire from work and therewith serve as points of reference to assess work and employment conditions (Hauff \& Kirchner, 2014, 2015). The entering of new generations into the labour market, the increasing participation of women in the labour force, or the migration of employees can lead to a shift in work values and therewith to a shift in the standards of good work.

The subjectivist perspective highlights in particular that each definition of a standard of good work is dependent on the perspective. Indeed, the evaluation of work and employment conditions is always embedded in a specific context, i.e. the particular socio-economic conditions at a specific time (Carré et al., 2012; Muñoz de Bustillo et al., 2011). Thus it is very difficult to establish a common standard of good work. This is also reflected in the particularities and differences in national and international labour and social law concerning, for example, employee protection rights, working time and wage standards, social security, and representation of employees' interests.

This Special Issue brings together research that addresses the issue of eroding and new standards of 'good work'. The first paper 'Employer Review Platforms - Do the Rating Environment and Platform Design affect the Informativeness of Reviews? Theory, Evidence, and Suggestions' evaluates the potential of employer review platforms for analysing and comparing job quality in different organizations. Using Kununu and Glassdoor as examples, Janis Cloos analyses if and how design aspects of employer review platforms affect how employees evaluate their current or former employer. His results show that the average review scores differ significantly between the different platforms and that reviews are also affected by factors such as employees' awareness of their impact on a company's reputation.

In the next paper on 'How Leadership Can Help to Mitigate the Dark Side of Autonomy: Results Based on the German Sample of the European Working Conditions Survey', Corinna Steidelmüller and Nils Backhaus analyse if job autonomy, which has often been considered the 'golden' standard of good work, might also have negative effects in terms of temporal boundarylessness (i.e. the risk that working hours and rest periods become blurred), which is in turn linked to unfavourable health outcomes. Thereby, they also analyse if constructive leadership behaviour can mitigate the potential risks of job autonomy. Among others, their results show that working time autonomy and working from home are positively associated with temporal boundarylessness and that leaders can lower the potential risks of working time autonomy.

The third paper 'Labour in the Board and Good Work: How to measure and evidence from Germany' discusses the characteristics and measurement of good work and analyses if and how board-level co-determination can help to promote good work. Robert Scholz illustrates the latter with three examples. The first shows how an executive board remuneration system in a strongly co-determined company can be linked to create a top-down process of realising good work. The second 
example shows how co-determination is associated with the independence of the personnel director in the executive board, as a pre-condition for realising good work. The third example shows how the embeddedness of co-determination in the supervisory board coincides with higher levels of vocational training in the companies.

The next paper 'Torn Between the Old and New World of Work: Insights Into the Modernised Semi-profession of the Fashion Industry' explores how persistent gender inequalities of the old world of work are amplified by the new world of work. Focusing on the fashion industry of Berlin, which entails deep gender inequalities in terms of segregation, low status and low pay, Alexandra Manske argues that the fashion industry is a modernised semi-profession that has been undergoing a market-driven professionalisation that reinforces gender inequalities since it erects new occupational barriers into the field of labour and aids to in polarising the still mostly female workforce in terms of status and rewards.

Last but not least Maria Norbäck and Alexander Styhre analyse in 'On the Precarity-Spectrum: Exploring Different Levels of Precariousness in Market-Mediated Professional Work' how the variability of market-mediated professional work affects professionals' experiences of precarity. Based on interviews with freelance journalists and life science professionals in startups, the authors can show that there is a 'spectrum of precarity' in which precariousness is distributed and experienced differently by professional groups. Factors that influence the degree of precarity include marketplace bargaining power, the form of economic remuneration (salary vs. piece rate) and the individual's general life situation.

\section{Acknowledgement}

This Special Issue originated from discussions during the Annual Conference of the Working Group for Empirical Personnel and Organizational Research (AKempor) held on September 26-27, 2019 at the University of Hamburg, Germany. We thank all the seminar participants for contributing interesting papers and comments. This work was supported by the Authority for Science and Research in Hamburg under the grant number LFF-FV 58-2016.

\section{References}

Aroles, J., Mitev, N., \& Vaujany, F.-X. (2019). Mapping themes in the study of new work practices. New Technology, Work and Employment, 34(3), 285-299. https://doi.org/10.1111/nt we. 12146

Carré, F., Findlay, P., Tilly, C., \& Warhurst, C. (2012). Job Quality: Scenarios, Analysis and Interventions. In C. Warhust, F. F. P. Carré, \& C. Tilly (Eds.), Are bad jobs inevitable? Trends, determinants and responses to job quality in the twenty-first century (pp. 1-22). Palgrave Macmillan. 
Eurofound. (2020). Living, working and COVID-19. Luxembourg. Publications Office of the European Union.

Grote, G., \& Guest, D. (2017). The case for reinvigorating quality of working life research. Human Relations, 70(2), 149-167. https://doi.org/10.1177/0018726716654746

Guerci, M., Hauff, S., \& Gilardi, S. (2019). High performance work practices and their associations with health, happiness and relational well-being: are there any tradeoffs? The International Journal of Human Resource Management, 1-31. https://doi.org/10.1080/09585192.2019. 1695647

Hauff, S., \& Kirchner, S. (2014). Changes in workplace situation and work values. Relations and dynamics within different employment regimes. Management Revue, 25(1), 27-49.

Hauff, S., \& Kirchner, S. (2015). Identifying work value patterns: Cross-national comparison and historical dynamics. International Journal of Manpower, 36(2), 151-168. https://doi.org/10.110 8/IJM-05-2013-0101

Holman, D. (2013). Job types and job quality in Europe. Human Relations, 66(4), 475-502. https://doi.org/10.1177/0018726712456407

ILO. (2013). Decent work indicators: Guidelines for producers and users of statistical and legal framework indicators. Geneva. International Labour Office.

Knox, A., Warhurst, C., Nickson, D., \& Dutton, E. (2014). More than a feeling: Using hotel room attendants to improve understanding of job quality. The International Journal of Human Resource Management, 26(12), 1547-1567. https://doi.org/10.1080/09585192.2014.949818

Leschke, J., \& Watt, A. (2014). Challenges in Constructing a Multi-dimensional European Job Quality Index. Social Indicators Research, 118(1), 1-31. https://doi.org/10.1007/s11205-013-0 405-9

Muñoz de Bustillo, R., Fernández-Macías, E., Esteve, F., \& Antón José-Ignacio (2011). E pluribus unum? A critical survey of job quality indicators. Socio-Economic Review, 9(3), 447475.

Walton, R. E. (1973). Quality of working life: What is it. Sloan Management Review, 15, 11-21.

Warhurst, C., \& Knox, A. (2020). Manifesto for a new Quality of Working Life. Human Relations, 001872672097934. https://doi.org/10.1177/0018726720979348 